\title{
두 종교를 동시에 살아가기
}

-『붓다 없이 나는 그리스도인일 수 없었다』에 대한 리뷰-

이찬수(서울대 통일평화연구원)

1. 책의 의미와 특징

1) 책의 이해를 돕기 위해

폴 니터(Paul F. Knitter, 1939 )는 대표적인 종교다원주의 신학자 이다. 한국에도 여러 차례 방문해 학자들과 토론하고 여러 종교 현장 을 경험한 바 있다. 그동안의 그의 신학을 한 마디로 요약하면 '종교해 방신학'이라 할 수 있다. 가난, 억압, 소외로부터의 해방을 중심 주제로 탐구해온 남미의 '해방신학'과 다양한 종교적 세계관을 신학적으로 소 화해내려는 '종교신학'이 그의 신학 안에는 일관되게 녹아 있다. 그는 오랫동안 사회적 속박과 경제적 소외로부터의 해방에서 구원의 사회 적 측면이 드러나며, 그 해방적 실천에서 다양한 종교들이 만난다는 사실을 강조해왔다. 그렇지만 그의 좀 더 근본적인 신학적 틀은 종교 
다원주의적 관점과 자세에서 더 잘 찾아진다. 궁극적 실재는 특정한 역사적 표현 속에 다 담기지 않으며, 특정 종교적 표현이 그 자체로 절 대적일 수 없다는 종교다원주의적 사유 체계가 그의 신학의 주요 축이 자 실질적인 근간을 이룬다. 인간 해방을 향한 실천적 관심을 다원주 의적 신학의 깊이 안에 균형감 있게 소화해온 대표적인 신학자라고 정 리해볼 수 있겠다.

2) 불교 없이는 나올 수 없었을 책

그의 주목할 만한 책, "붓다 없이 나는 그리스도인일 수 없었다』 (Without Buddha I Could not be a Christian, 클리어마인드, 2011)가 최근 한국어로 출판되었다. 그의 기존 사상 안에도 다양한 종교적 세 계관 등이 두루 녹아 있지만, 이 책에서는 특별히 불교로부터 받은 영 향과 충격을 집중적으로 반영하고 있다. 불교가 자신의 신학 형성에 끼쳐온 영항을 실존적이고 고백적으로, 차분하고 진지하게 진술하고 있다. 불교를 녹여내며 신학을 한다는 것이 무엇인지, 그렇게 정립된 신학의 모습은 어떤 것인지, 진지하면서도 비교적 평이한 언어로 정리 하고 있는 것이다.

원 제목을 정확하게 번역하면, "만일 붓다가 없었다면 나는 그리스 도인일 수 없었을 것이다"가 된다. 우리말 문장이 다소 길어 역자가 축 약했겠지만, 이 책은 제목에서부터 니터 자신의 그리스도적, 신학적 정 체성을 가능하게 해주었던 종교를 불교에서 찾아오고 있었다는 사실 을 명확하게 밝히고 있다. 일반 그리스도교인이 보면 그리스도교를 불 교의 하위 범주에 놓는 듯한 제목에 분개할 수도 있을 정도로 도발적 이다.

하지만 차근차근 읽다보면 알게 될 일이지만, 이 책은 참으로 솔직 
하고 진솔한 신학 사상서이기도 하다. 불교를 신학적 실존 안에 소화 해오느라 겪었을 저자의 고민의 깊이가 느껴지는 책이다. 특히 동양 사상의 근간이 되는 불교를 그리스도교의 깊이 안에 융합해내되, 학자 연하지 않으려는 진솔한 태도에서 저자의 인격과 신앙의 깊이가 와 닿 는 책이기도 하다.

이 책은 불교나 그리스도교에 대한 단순한 비교 이론서가 아니다. 이 책에서 불교나 그리스도교의 교리만을 찾으려 한다면, 그것은 이 책의 절반도 파악하지 못하는 것이다. 세계의 위대한 종교 전통을 신 학적이고 신앙적으로 체화시켜온 양심적 지식인의 구도적 여정을 읽 어내는 것이 중요하다. 불교와 그리스도교를 동시에 살아내기 위한 구 도적 자세를 읽어널 때에야 이 책의 핵심을 읽는 것이 된다. "두 전통 에 속하기"(Double-religious-belonging)가 그의 학문과 삶의 지향점 이다.

2. 요지와 서술 방식

1) 불교로 건너갔다가 그리스도교로 돌아오기

니터는 1970년대 이래 존 듄(John Dunn)이 말한 “우리 시대의 영적 모험"을 스스로 계속해왔다고 자평한다.

(존 듄의 신학적 방법이란) 가능한 한 개방적이고 신중하고 인격적인 방식으로 다른 종교전통으로 건너갔다가 자기 종교전통으로 돌아오는 것이다. 그것은 다른 이의 '종교적 구두'를 신고 걷는 것이 자기 종교 전통을 이해하고 그것과 조화롭게 지내는 데 어떤 도움이 되는지를 알아 보는 모험이다.(39쪽) 
니터는 이 책에서 불교라는 구두를 신고 불교적 세계를 여행한 뒤 이전과는 달라진 모습으로 그리스도교로 되돌아오는 영적 여행을 잘 보여준다. 그러한 구도적이고 지성적인 여행은 니터가 이 책을 저술하 는 방식에서 일관되게 드러나고 있다. 그는 이 책의 모든 장(章)마다 기존 신학적 세계관에서 불교적 세계관으로 건너갔다가 다시 신학의 세계로 되돌아오는 과정에 신학적 의미와 언술이 불교로 인해 얼마나 달라질 수 있는지를 적절히 보여주고 있다. 그리고 그렇게 달라진 신 학이 신학의 변질이나 타락이 아니라 온전한 신학으로의 전환이라는 사실도 진지하고도 열정적으로 제시하고 있다.

(니터 스스로 요약하고 있듯이) 이 책이 시종일관 다루고 있는 주제는 …무한자와 유한자 사이, 불교적으로 말하면 공과 색의 상징 사이, 그리 스도교 용어로는 영과 세계 사이의 근본적이고 역동적인 관계는 양자가 서로 안에 있고 서로로 인해 존재하는 관계라는 것이다. 그들은 비록 전혀 다르지만 서로 안에 있고 함께 존제한다. 이것이 우리가 1장부터 4장까지 탐구한 것이다. 그리고 '구원'과 '영성'은 이런 합일, 일치, 둘 안에 하나인 상태를 깨닫고, 그것을 영적으로 깊이 느끼며 일상생활에서 살아내는 것이다. 5 장과 6 장이 이에 대한 것이었다. 불교는 그런 신비적, 합일적 체험이 하느님의 공동체의 이상에 이 세계가 좀 더 가까워지도록 하려는 운동가로서의 내 노력의 원천이 되고 방향을 제시하게 해야 한다 는 것을 분명히 하도록 도와주었다.(362쪽)

불교를 신학적 활동의 원천으로 삼는다는 것은 무엇일까. 불교로 건 너갔다가 다시 돌아온 신학의 언어는 이전과 어떻게 달라지는 것일까. 이 책에서 깊이 정리하고 있는 다양한 사례들을 간단하게나마 하나씩 살펴보자. 
2) 불교의 눈으로 신학 다시 보기

흔히 일반 그리스도교인은 신을 인간의 확대판처럼 생각하는 경향 (신인동형론)이 있다. 이 점은 분명히 극복의 대상이다. 하지만 니터는 신의 인격성을 단순히 폐기하지는 않는다. 인격성과 관련된 언어를 반 대하거나 절제하는 불교적인 시각을 수용하면서, 그는 신에 대한 인격 적 표현들은 인간의 내면을 평화롭게 하는 근거이자 타자를 돌보는 능 력을 나타내주는 일종의 상징 언어라고 해석한다. 불교의 지혜와 자비 도 인격적 신관 안에 녹여낸다.(104-105쪽) 신의 인격성은 사람을 살 게 해주는 근원적 능력의 차원에 대한 상징 언어와 관련되어 있다는 것이다.

그는 신과 창조 세계를 둘도 하나도 아닌, 불이(不二)의 관계로 묘사 하고(70-71쪽), 신을 명사, 존재, 철학으로서보다는 동사, 활동성, 윤리 로 이해하며(110쪽), 보리심(bodhi-citta)을 모든 생명 안에서 고동치 고 있는 자애심의 정수 내지 감동을 주는 영의 인격적 능력으로 해석 한다.(109쪽) "말은 전적으로 달은 아니지만 정말로 달"이라며, 불교의 언어론을 적극적으로 해석하기도 한다.(153쪽) 언어는 수단이지만, 수 단 없이 대상이 지시되지는 않는다는 점에서, 언어의 기능을 상징적 차원에서 심화시켜 수용해내려는 것이다. '상징'이기에 집착의 대상이 되어서는 안 되는 것은 물론이다.

예수가 “하느님의 아들"이라는 신조는 신성이 하늘로부터 '내려와' 예수에 게 임했기 때문에 형성된 것이 아니다. 그에 의하면 "하느님의 아들" 은 인간 예수가 내면에 있는 영의 존재와 활동을 깨닫고 자각하 고 반응하면서 제자들에 의해 그렇게 불리게 된 결과이다. 이런 해석 은 대체로 현대 신학자들도 동의하는 내용이지만, 니터에게서는 무언 가 다른 독특성이 더 보인다. 그에 의하면, 고타마가 깨달아 '붓다'로 
불리게 되었듯이, 예수도 어떤 스승을 통해 신성을 '깨달았기에' 결국 하느님의 아들로 불리게 되었다고 한다. '깨달음'을 강조하는 것 (226-228쪽)은 확실히 다른 신학자들과 차별적이다. 그에게 "하느님의 아들"은 "깨달은 이"와 비슷한 맥락에 있다.

구원도 깨달음의 차원을 지닌다. 그는 이렇게 말한다: "불교는 내게 예수의 신성을 깨달음의 결과로 이해할 수 있게 해주었다. 그리고 그 리스도인들이 말하는 구원이란 우리 자신의 깨달음, 곧 하느님의 자녀 인 우리의 신성을 발견하는 것임을 이해하게 해주었다."(230쪽) 그렇 게 볼 때 "이제는 내가 사는 것이 아니라 그리스도가 내 안에서 사는 것"(갈라디아서 2,20 )이라는 바오로의 구원관이 더 잘 이해된다고 그 는 본다. 그에게 “구원받음은 그리스도 안에 있는 것이다."(231쪽)

그리스도인이 입에 달고 살다시피 하는 그리스도의 '유일성'도 수량 적 의미의 '하나'가 아니라, 자신의 배우자나 연인에 대해 "그이 같은 사람은 없어," "당신이 세상에서 가장 아름다워"라고 말하는 것과 같 은 고백의 언어, 사랑의 언어라고 해석한다.(240-242) 부활도 "그리스 도가 내 안에 나의 모습으로 살아있음을 느끼고 긍정하는 것"이 된 다.(248-249) 부활이 단순히 미래적 희망이기만 하지 않고, 지금 여기 내 안에서 벌어지고 있는 사건이 되는 것이다.

3) 불교적 두레박으로 그리스도교적 진리 길어 올리기

죽음 및 영생론과 관련해 불교적 무아론에서 받은 통찰도 무엇보다 크다고 그는 고백한다. 그에 의하면, 무아(無我)란 “진정한 정체성이 개체적 자아를 넘어 더 큰 실재인 상호의존의 일부가 되고, 자비롭게 그것에 기여하게 된다는 의미"이다.(167쪽) 따라서 죽음 이후에 무언 가 개체성이 지속되리라는 흔한 상상보다는, 순간순간 집착 없이 충실 
하게 사는 삶이 죽음 내지 영생의 본질을 잘 이해하게 해준다. 그것이 더 큰 실재(하느님) 안에 사는 삶이고, 틸리히가 말하는 “영원한 현 재"(Etemal Now)이기도 할 것이다.

이런 식으로 니터는 신학에 대한 불교적 조명을 통해 신학과 그리스 도교를 훨씬 더 잘 보게 되었다고 내내 고백한다. 물론 이러한 고백의 목적은 그리스도교적 진리 자체의 한계를 확인했기 때문은 아니다. 불 교적 도전을 수용하고서 그리스도교적 언어가 지시하는 세계 속으로 깊게 들어가면 그동안 잘 보지 못했던 본연의 진리가 더 잘 보인다는 생생한 경험을 나누는 데 있다. 그는 그리스도교적 진리의 우물도 깊 지만, 길어 올리는 두레박에 구멍이 나 있어서 그동안 진리의 생수를 충분히 길어 올리지 못했다고 말한다.(270쪽) 이런 비유적 표현에 담 겨있는 것은, 두레박의 구멍을 메움으로써, 달리 말해 그리스도교적 우 물에서 불교적 두레박을 사용함으로써(291쪽), 그리스도교적 진리의 생수를 더 잘 길을 수 있게 된다는 것이다. 그렇게 길어진 그리스도교 적 진리는 불교적 진리와 다른 것만은 아니라는 것이 이 책이 표현하 려는 깊은 의중이기도 하다. 두 종교를 단순히 섞으려는 것이 아니다. 모든 것은 결국 그리스도교적 진리를 더 깊게 보려는 데 그 목적이 있 는 것이다.

그의 진솔한 주장들은 단순한 이론적 연구의 결과가 아닌, 위빠사나 나, 선(276-278쪽) 같은 불교적 수행을 오래 체험해온 결과이기도 하 다. 그에 의하면 그리스도인도 불교적 수행을 신앙적 실천의 근간이자 모델로 삼아야 한다. 분별지를 넘어선 '마음챙김'으로 실천적 자비를 드려내려는 불교적 수행은 그리스도교적 성사(聖事)로 삼기에 충분하 다. 그리스도인에게 세례, 성찬 등이 ‘신의 거룩한 일'[聖事]이라면, ‘침 묵'이야말로 영적 수행의 핵심이 되어야 한다. “침묵의 성사”가 요청된 다는 것이다.(289-290쪽) 침묵의 영성체 안에서 그리스도를 받아들이 
고,(293쪽) 무집착적 말없음을 통해 '하느님 너머의 하느님'을 찾을 수 있다는 것이다.(297쪽)

그럴 때 개인적 평화가 이루어지고 사회적 평화로 이어진다. 틱낫한 이 말하는 '평화롭기'(Being peace)를 그리스도교적 언어로 번역하면 '그리스도 되기'(Being Christ)가 된다. 그리스도는 단순히 하늘에 모 셔둔 초월적 믿음의 대상이 아니다. 사실상 그리스도인의 내적 주체이 다. 그것을 깨닫는 것이 신앙의 목표이며, 그렇게 그리스도인이 그리스 도가 될 때, 깊은 평화가 성취된다.(341쪽) 언어의 외형은 다른 듯하지 만, 그가 보건대 그리스도교적 언어가 지시하는 세계 속에는 불교적 세계와도 통하는 깊은 진리가 담겨있다. 그런 식으로 불교로부터 받은 통찰을 진지하고 평이하면서도 깊이 있게 신학의 언어로 기록해낸 책 이 바로『붓다 없이 나는 그리스도인일 수 없었다』인 것이다. "불교는 그리스도교의 우물의 깊고 신비로운 물을 퍼 올릴 수 있는 두레박을 그리스도인들에게 제공한다."(291쪽)

4) 불교는 그리스도교의 먼지를 닦아준다

불교의 눈으로 본다고 해서, 불교적 수단을 사용한다고 해서 그리스 도교적 정체성이 사라지는 것은 아니다. 불교의 무아적 세계관을 수용 한다고 해서, 가령 축음 이후의 세계를 쉽게 외면하거나 부정하는 것 은 아니다. 니터는 죽음 이후를 긍정하며 나아가 기대하기까지 한다. 긍정하고 기대하되, 구체적이고 제한적인 말로 다 담아낼 수 없는 '신 비'의 영역 차원에서 그렇게 한다. 자신의 장례미사의 주제를 “신비를 고이 간직하라"로 삼고 싶다며 다음과 같이 말할 때 그런 마음이 잘 드러난다. 
신비를 존중하고 그것을 범하지 말라. 그것을 그대로 놓아두어라. 너무 많은 말은 신비를 희석시킨다. 오직 내가 말하고 싶은 것은 신비는 풍부 한 어둠이며 보잘 것 없고 늙은 나보다 훨씬 더 큰 존재일 거라는 점이다. 신비는 내가 지금 상상할 수 있는 것보다 더 실제적이고 더 큰 것이리라 그러므로 죽는 것은 좋은 것이다. $\cdots$ 이 마지막 순간에도 어떤 것이 계속 될 것이다. 이 계속되고 있는 것은 사랑스러운 신비의 일부이고, 불교 용어로는 사랑스러운 다르마의 일부이다.(186-187쪽)

불교철학 내지 세계관을 외면하지 않고 도리어 다 담아내려는 의도 로 사용된 언어가 '신비'인 셈이다. 이런 식으로 니터에게 불교는 두터 운 먼지에 쌓여 드러나지 않았던 그리스도교적 진리가 충실히 드러나 도록 깨끗이 닦아주는 수건과 같다. 불교에서 받는 도움이 무엇보다 크니, 그리스도교적 진리의 발견을 위해서라도 불교라는 '수단'을 사용 할 필요가 있다고 그는 진지하게 제안한다.(227, 291쪽) 수단이되, 진리 로서의 수단이다. 이 책은 그러한 사실을 진솔하게 엮어나가고 있다.

\section{3. 불교적 그리스도인, 니터라는 사람}

이쫌 되면, 그의 정체성이 다시 궁금해진다. 그는 한때는 가톨릭 사 제였던 그리스도교 신앙인이고, 여전히 명망 있는 신학자이다. 그러나 불교를 체화해 자신의 삶과 신학 안에 녹여낸, 스스로의 표현대로 하 면 “불교적 그리스도인"이다. 그는 자신의 종교적 정체성을 이렇게 정 리하며 규정한다.

나는 스승인 라마 매크란스키(그는 보스톤 대학의 불교학과 비교신학 교수이기도 하다)와 진지하게 대화한 후 불교에 귀의하고 미국 족첸 
공동체의 일원으로서 '보살서원'을 하기로 결정했다. 나는 '연꽃치유자' 라는 법명도 받았다. 그것은 공식적인 것이다. 이제 나는 불교 신분증도 가지고 있다. 나는 1939년에 가톨릭 영세를 받았고, 2008년에 불교에 귀의했다. 나는 지난 수 십 년 동안의 나를 이렇게 부를 수 있다. 나는 불교적 그리스도인이다.(392)

물론 그로 하여금 불교에 매력을 느끼게 하고 진지하게 소화하도록 요청하는 문화적이고 정신적인 지평은 그리스도교이다. 그는 어린 시 절부터 그리스도교 안에서 살아왔다. 그리스도교는 그에게 기쁨과 위 로와 보람, 그리고 갈등과 고민을 동시에 안겨주었다. 이 그리스도교가 깊은 곳에서 불교를 삶 안에 받아들이도록 해주는 원천인 것이다. 그 리고 그렇게 받아들인 불교는 동시에 신학을 신학답게 해주는 근간으 로 작용한다. 그래서 그에게 그리스도교와 불교는 이원론적이거나 이 분법적이지 않다. 그는 이렇게 말한다.

나는 두 전통에 속하기(Double-religious-belonging)가 그리스도교 공 동체 안의 최첨단임을 군게 믿고 희망한다. 나는 이 최첨단이 교회가 되는 새로운 길로 이끌 거라고 믿고 희망한다.(393쪽)

태생 그리스도교인이고 일급 신학자이지만, 두 종교를 단순 병렬식 으로가 아니라, 하나로 녹여내 살아가는 것이 가능하다는 것을 니터는 이 책에서 웅변적이고 체험적으로 보여준다. 자신의 신앙적 혹은 신학 적 경험들을 적재적소에 반영하며 때로는 신학적 자서전의 형태로 저 술해 나가는 모습에서 구도적 생생함이 잘 느껴진다. 이런 방식으로 니터는 불교를 그리스도교 안에 창조적으로 소화시켜낸 신학자의 전 형을 보여주고 있다. 


\section{4. 아쉬움이 있다면}

이 책을 읽으며 아쉬움도 있었다. 니터의 불교 이해는 대단히 진지 하고 실존적이지만, 적어도 이 책에서 나타나는 그의 불교 이해의 폭 은 기대만큼 넓지 않다. 수 십 년 불교를 공부하고 체화시켜왔다는 저 간의 경험치에 비해 이 책에서 사용하고 있는 불교 언어 혹은 세계관 은 다소 제한적이다. 무아, 열반, 붓다 등의 언어와 개념을 반복해 사용 하고 있는 모습에 담긴 불교는 분명히 진지하지만 때로는 단순하기도 하다.

물론 언어의 단순성은 학문의 수준이 일정한 경지에 이르렀다는 증 거도 된다. 이 책은 그의 신앙과 인격이 완숙한 경지에 이르렀다는 사 실을 잘 반영해준다. 그런 점에서 불교적 세계관의 단순성은 학문적 솔직함과 겸손함의 표현일 수 있다. 저자 자신의 삶과는 상관없이 현 란한 언어를 구사하며 그저 이론을 위한 이론에 머물고 마는 상당수 이론서들과 이 책은 확실히 차별적이다.

하지만 이 책에서 줄곧 인용하며 설명하는 무아, 열반, 붓다 등의 개 념과 의미를 넘어 중관(공), 유식, 밀교, 그리고 선(禪) 등의 언어와 세 계관도 자연스럽게 체화해 신학을 설명했더라면 신학적 깊이와 다양 성이 훨씬 더 잘 표헌되지 않았겠나 하는 아쉬움이 든다. 이 책은 역량 있는 신학자가 만년에 내놓은 구도적 회심작답게, 분명하면서도 쉽고 깊으며, 실존적이고 객관적이다. 하지만 불교적 언어와 세계관에 대한 '좀 더 깊은' 이해가 담겨있었더라면 좋았겠다는 아쉬움이 드는 것은 사실이다. 이것은 저자와 비슷한 경험을 해오고 있는 논평자로서 학문 적이면서도 구도적인 모델을 더 깊게 보고 싶은 아쉬움의 표현이기도 하다.

물론 그런 아쉬움은 논평자만의 것이다. 논평자에게 그런 아쉬움이 
느껴진다고 해서 이 책의 가치가 반감되지는 않을 것이다. 삶은 결국 단순한 것이고, 이 책은 단순한 삶을 종교적이고 지성적인 차원에서 치열하게 살아내려는 구도적 여정기라는 점에서 그렇다. 영적 모험기 가 현란하거나 복잡할 이유는 없을 것이다. 그런 현란함은 도리어 사 치이자 위선일 수도 있겠기 때문이다.

불자든 그리스도인이든 니터만큼 다른 문화권의 언어를 차열하게 소화해, 신학적 양심에 솔직하게 녹여내는 일을 깊이 있게 보여주는 일은 어렵다. 이 책은 구도적이고 종교적인 양심을 가지고 인생의 마 무리를 진솔하게 해나가는 탁월한 학자의 모범을 잘 보여준다고 할 수 있다.

그 밖에 칭찬하지 않을 수 없는 일은 우리말 번역 작업이다. 번역이 비교적 매끄러워 읽기에 편안하다. 번역자의 역량이 느껴진다. 번역자 중 한 사람은 니터 교수 지도하에 신학 박사과정을 밟고 있는 장래가 촉망되는 신학자이고, 다른 한 사람은 현직 의사이다. 정신적 치유자 신학자와 육체적 치유자 의사가 동서양 사유체계의 근간이 되는 불교 와 그리스도교의 영적 교차점이 되는 책을 함께 번역해낸 것도 그 교 차점에서 진정한 치유가 일어난다는 사실을 보여주는 상징처럼 느껴 져 의미 있게 다가왔다. 